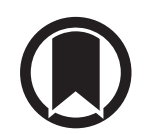

CrossMark

\title{
Digital health for the End TB Strategy: developing priority products and making them work
}

Dennis Falzon ${ }^{1}$, Hazim Timimi ${ }^{1}$, Pascal Kurosinski ${ }^{2}$, Giovanni Battista Migliori ${ }^{2,3}$, Wayne Van Gemert ${ }^{1}$, Claudia Denkinger ${ }^{4}$, Chris Isaacs ${ }^{4}$, Alistair Story ${ }^{5}$, Richard S. Garfein ${ }^{6}$, Luis Gustavo do Valle Bastos ${ }^{7}$, Mohammed A. Yassin ${ }^{8}$, Valiantsin Rusovich ${ }^{9}$, Alena Skrahina ${ }^{10}$, Le Van Hoi ${ }^{11}$, Tobias Broger ${ }^{4}$, Ibrahim Abubakar ${ }^{12}$, Andrew Hayward ${ }^{13}$, Bruce V. Thomas ${ }^{14}$, Zelalem Temesgen ${ }^{15}$, Subhi Quraishi ${ }^{16}$, Dalene von Delft ${ }^{17}$, Ernesto Jaramillo ${ }^{1}$, Karin Weyer ${ }^{1}$ and Mario C. Raviglione ${ }^{1}$

Affiliations: ${ }^{1}$ Global TB Programme, World Health Organization, Geneva, Switzerland. ${ }^{2}$ European Respiratory Society, Lausanne, Switzerland. ${ }^{3}$ WHO Collaborating Centre, Fondazione S. Maugeri, Tradate, Italy. ${ }^{4}$ FIND, Geneva, Switzerland. ${ }^{5}$ Find \& Treat, University College London Hospitals, London, UK. ${ }^{6}$ University of California San Diego School of Medicine, La Jolla, CA, USA. ${ }^{7}$ Management Sciences for Health, Arlington, VA, USA. ${ }^{8}$ The Global Fund to Fight AIDS, Tuberculosis and Malaria, Geneva, Switzerland. 'WHO Country Office, Minsk, Belarus. ${ }^{10}$ Republican Scientific and Practical Centre for Pulmonology and Tuberculosis, Minsk, Belarus. ${ }^{11}$ National TB Programme, Hanoi, Viet Nam. ${ }^{12}$ University College London, London, UK. ${ }^{13}$ Farr Institute of Health Informatics, University College London, London, UK. ${ }^{14}$ The Arcady Group, Richmond, VA, USA. ${ }^{15}$ Mayo Clinic, Rochester, MN, USA. ${ }^{16} \mathrm{ZMQ}$, New Delhi, India. ${ }^{17}$ TB Proof, Cape Town, South Africa.

Correspondence: Dennis Falzon, Global TB Programme, World Health Organization, 20, Avenue Appia, CH-1211, Geneva 27, Switzerland. E-mail: falzondQwho.int

ABSTRACT In 2014, the World Health Organization (WHO) developed the End TB Strategy in response to a World Health Assembly Resolution requesting Member States to end the worldwide epidemic of tuberculosis (TB) by 2035. For the strategy's objectives to be realised, the next 20 years will need novel solutions to address the challenges posed by TB to health professionals, and to affected people and communities. Information and communication technology presents opportunities for innovative approaches to support TB efforts in patient care, surveillance, programme management and electronic learning. The effective application of digital health products at a large scale and their continued development need the engagement of TB patients and their caregivers, innovators, funders, policy-makers, advocacy groups, and affected communities.

In April 2015, WHO established its Global Task Force on Digital Health for TB to advocate and support the development of digital health innovations in global efforts to improve TB care and prevention. We outline the group's approach to stewarding this process in alignment with the three pillars of the End TB Strategy. The supplementary material of this article includes target product profiles, as developed by early 2016, defining nine priority digital health concepts and products that are strategically positioned to enhance TB action at the country level.

@ERSpublications

Priority digital health products will be profiled and developed to support the scale-up of WHO's End TB Strategy http://ow.ly/4mRRjR

This article has supplementary material available from erj.ersjournals.com

Received: Feb 272016 | Accepted after revision: April 102016 | First published online: May 262016

Support statement: Both the consultation and the agenda for action received crucial funding and technical and logistical support from the European Respiratory Society. The US Agency for International Development was a principal salary supporter of the World Health Organization staff involved in this article. Funding information for this article has been deposited with FundRef.

Conflict of interest: P. Kurosinski is an employee of the European Respiratory Society. Further disclosures can be found alongside this article at erj.ersjournals.com

The content of this work is (C)the authors or their employers. Design and branding are CERS 2016. This version is distributed under the terms of the Creative Commons Attribution Non-Commercial Licence 4.0. This is one of a selection of articles published as ERJ Open papers, as part of an initiative agreed between the European Respiratory Society and the World Health Organization. 


\section{Introduction}

Tuberculosis (TB) remains an urgent public health threat and a leading infectious cause of death worldwide [1]. In 2014, the World Health Assembly resolved to end the global TB epidemic by 2035 [2]. This led to the elaboration of the End TB Strategy by the Global TB Programme of the World Health Organization (WHO) and its partners for the 20 years post-2015 [3,4]. The End TB Strategy's vision is to make the world free of TB, with no deaths, disease and suffering due to the disease. For the global TB epidemic to be brought to an end by 2035, a drastic reduction in TB incidence and mortality will be needed. The strategy is structured around distinct components and achievement of its goals will depend on action on its three pillars, namely: 1) expanding the scope and reach of interventions for TB care and prevention, with a focus on efficient, high-impact and patient-centred approaches; 2) maximising the benefits of health and development policies and systems, by engaging a broader cross-section of actors across government, communities and the private sector; and 3) pursuing new scientific knowledge and innovations that can dramatically change TB prevention and care. The End TB Strategy is aligned to the broader post-2015 development framework mapped out by the United Nations Sustainable Development Goals (SDGs) [5]. The SDGs seek to build upon the actions catalysed by the Millennium Development Goals (MDGs) until 2015 and to complete what the MDGs did not achieve. The SDGs' vision is to improve the economic, social and environmental dimensions of development. A plan of action to strengthen universal peace and eradicate poverty by 2030 has been formulated, and the 17 SDGs and their 169 targets are geared towards this [6]. TB care and prevention fit primarily under SDG 3, which is devoted to health; however, activities needed to accomplish the End TB Strategy will need to engage other SDG domains, such as supporting infrastructure and innovation (SDG 9), reducing inequalities (SDG 10) and strengthening alliances with partners towards common ends (SDG 17).

Innovative approaches to care and prevention are needed to achieve the ambitious goals of the End TB Strategy and the SDGs. The operationalisation of the End TB Strategy requires that national TB programmes and other stakeholders re-examine how their respective objectives must evolve in order to align with the post-2015 trajectory.

Electronic health (eHealth) and mobile health (mHealth), collectively referred to as "digital health", occupy an increasingly important space in preventive and curative interventions in both affluent and resource-constrained settings. Digital health is destined to play a pivotal role in the implementation of key activities to achieve a number of SDGs and to end the global TB epidemic, be they old or new, or directed at patient care, surveillance, programme management, advocacy, staff development or the engagement of civil society (figure 1) [7]. These interventions will also be needed to implement most of the eight priority action areas to eliminate TB in low-incidence countries [8]. In recent years, TB programmes and technical partners worldwide have initiated several digital health projects in order to enhance the reach and effectiveness of their work. Some of these efforts have shown promise but many have lacked the scale, the end-user ownership and the coordination needed to achieve population-level impact.

The existing state of the art of information and communication technology (ICT) and its "next-generation" enhancements present opportunities to broaden the scale of action and to overcome barriers to programmatic interventions in TB, which appear insurmountable even today. Fresh thinking on how to adopt, implement, market and sustainably support these technologies would, however, be needed.

In April 2015, WHO established a Global Task Force on Digital Health for TB (referred to henceforth in this paper as the Task Force) to promote the integration of digital health into national operational plans to implement the End TB Strategy [9]. This paper expands upon the content of the WHO digital health Agenda for Action created by this enterprise and in collaboration with the European Respiratory Society (ERS) [10]. In addition, it describes the process by which the Task Force and other partners identified digital health products that are strategically positioned to address the challenges faced by TB patients and health professionals. A key outcome of this process is the development of a set of target product profiles (TPPs) by the Task Force: a detailed description of the TPPs can be found in the supplementary material.

\section{Methods and rationale}

Process

On February 25-26, 2015, WHO and the ERS held a joint technical consultation on the role of digital health for TB and tobacco control in Geneva, Switzerland [11, 12]. Ahead of this consultation, in early 2015, WHO surveyed public views on the priority products to be focused upon during the discussions using an online questionnaire. The consultation was attended by close to 100 participants and was organised into tracks of work devoted to each of the four functions identified by the WHO conceptual framework for digital health in the TB response, namely patient care, surveillance and monitoring, programme management, and electronic learning (eLearning) [13]. The programme management function was devoted to the strengthening of laboratory information systems, a critical priority for the TB manager. Each of the tracks focused on one or more digital health products selected by its members. 


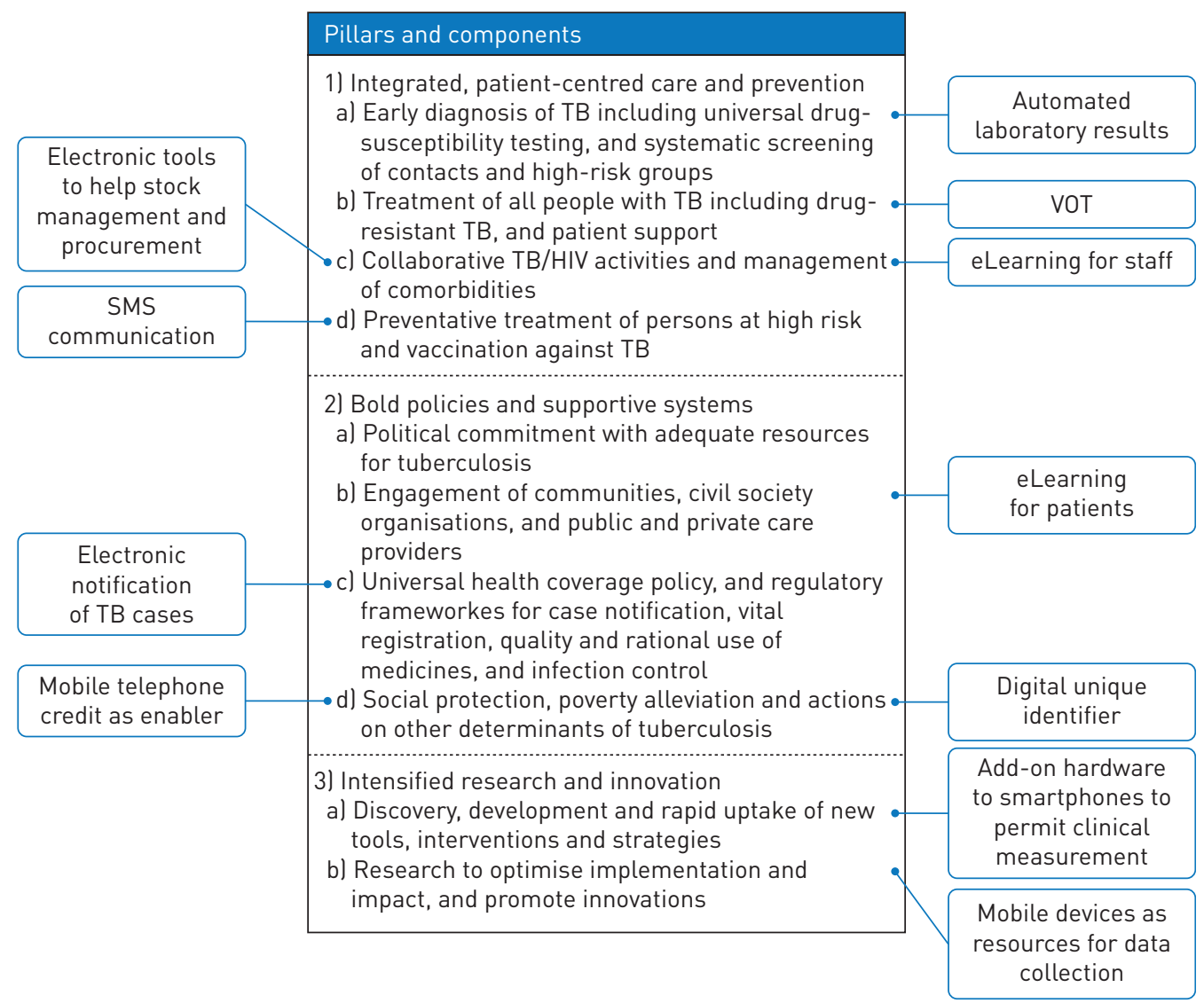

FIGURE 1 Examples of common digital health products and their potential contribution to different components of the End TB Strategy. TB: tuberculosis; VOT: video (virtually) observed therapy; eLearning: electronic learning; SMS: Short Message Service.

The characteristics of the digital health products were described using TPPs. TPPs define the features of the desired solutions in sufficient detail and transparency to stimulate more interest from potential developers [14]. They are dynamic discussion tools that are revised in the development process. Where they apply to the creation of software, the TPP approach shares many characteristics with behaviour-driven development [15]. The TPP approach has recently been used to focus the views of multiple stakeholders and developers on the priority diagnostics required for $\mathrm{TB}[16,17]$. One of the members of the Task Force was recently involved in finalising a detailed TPP for electronic medication monitors for use in patients on TB medication following positive findings from a trial of its use (Bruce V. Thomas, personal communication) [18]. This product is scheduled for large-scale roll out in high TB burden settings from 2016.

These recent developments motivated the Task Force and other partners who were involved in this initiative to follow a similar approach in their work. The digital health TPPs are expected to serve users at both national and global levels; they will guide developers to come up with solutions tailored to the problems faced by national TB programmes, and to steward the implementation of these new concepts, and ensure a more systematic method of collection and reporting of evidence.

This article presents the TPPs as they were developed until February 2016 as a result of an iterative consultative process, which started during the technical consultation and followed electronically thereafter (table 1 and supplementary material). The description of each of the TPPs is structured in nine identical sections, namely: 1) goals, scope and description; 2) target end-users; 3) value to the target end-user and other beneficiaries; 4) strategic fit; 5) rationale for prioritisation; 6) optimal requirements; 7) minimal requirements; 8) factors for success; and 9) key risks (threats) for its development. At this stage of development, the descriptions do not contain comprehensive details sufficient for a developer to create a product. The TPPs will eventually need to be refined by developers into technical specifications for the design of concrete products. Designing, building and rolling out a digital application needs to embrace a broad cross-section of representative users and policy-makers, one that engages with them and that supports their efforts [19]. This will require additional work to test concepts at the country level and study which processes need to happen alongside to ensure successful adoption, such as human resource 
TABLE 1 Summary of target product profiles (TPPs) for the End TB Strategy las of February 2016)

Function TPPs

Patient care

Surveillance and monitoring

Programme management eLearning
1) Video treatment support (VOT) for TB patients via mobile telephones

2) eHealth portal to improve TB and tobacco care

3) Digital dashboard for TB indicators and epidemiological trends

4) Digital notification of TB cases

5) Digital application for active TB drug safety monitoring

6) Diagnostic device connectivity for TB

7) Information resources platform for patients on TB and smoking cessation

8) Web-based training for health professionals on TB and smoking cessation

9) Clinical decision support systems for TB treatment and smoking cessation

eLearning: electronic learning; VOT: video (virtually) observed therapy; TB: tuberculosis; eHealth: electronic health.

development and changes to regulations. Moreover, the introduction of new technologies into a setting needs to complement others that are already in place, and to fit within the eHealth framework that a country may already have and within which these technologies are expected to function $[20,21]$.

\section{TPPs for digital health for the End TB strategy: criteria for selection}

The choice of products and associated activities were premised upon the pressing needs and realities of TB programmes, upon existing evidence and knowledge about the effectiveness of certain digital health interventions, and the rapid advances in technologies of which potential users may be unaware. Firstly, there is a need for an articulated and step-wise approach to develop comprehensive digital health solutions to support the End TB Strategy and other associated policies that exist (e.g. eliminating $\mathrm{TB}$ in low-incidence settings $[8,22,23])$, in particular, to limit fragmentation of efforts leading, for instance, to parallel systems, redundancy and waste of resources. The products and concepts defined by the TPPs were selected to complement each other in a given setting, which would be the desirable approach to implementation in contrast to the creation of independent standalones; they should thus be developed in parallel, ideally at comparable speeds towards completion [10]. Secondly, opportunities should be sought to integrate and seek synergies with promising ICT initiatives, both within healthcare and beyond, so as to increase the efficiency, scalability and sustainability of efforts. Thirdly, managers and other decision-makers may not be well informed about which digital health technologies could be most appropriate to match their needs in TB prevention and care work. Fourthly, on the practical side, the Task Force opted to keep the first batch of TPPs to a manageable set.

Based on these considerations, the members of the work groups selected one to three products deemed to be advantageously placed to secure gains to that particular function at a large scale, in the near future. This choice should not be construed as a recommendation for the immediate, large-scale implementation of these products, which at times represent emerging technologies with incomplete knowledge on their effectiveness. Moreover, the authors acknowledge that several promising concepts deserving of investment would not be captured in the initial wave of TPPs. These include telemedicine interventions, apart from video (virtually) observed therapy (VOT), which is described here, as well as electronic monitoring of the use of medication containers [18, 24-26]; computer-assisted diagnostic tools, particularly in connection with imaging techniques such as digital radiography [27]; aids to planning the supply of medicines and forecasting their consumption [28]; "clip-on" hardware that converts smartphones into clinical measurement devices [29-32]; and others. The Task Force encourages such initiatives and intends to stay abreast of similar developments led by technical or funding agencies to take forward additional TPPs to the nine included at this stage.

\section{Justification for digital health in TB care and prevention}

The pace with which ICT has developed and diversified over the years can only be described as revolutionary. By the end of 2015, half of the world's population had a mobile telephone subscription, representing more than a doubling in coverage within the space of 5 years (https://gsmaintelligence.com/). About $40 \%$ of the world's population can access the Internet, although coverage and broadband speed differ substantially between and within regions [33]. Smartphones are progressively replacing less sophisticated mobile phones all over the world, a trend primarily driven by uptake in developing countries. Developments such as these could present huge openings for health care, as users become better informed about lifestyles that pose a risk to health and about access to services, while health professionals enjoy 
more efficient means to keep their knowledge up to date and maintain contact with their patients to follow up on their healthcare needs.

New opportunities are created for public health researchers, health system managers, patients and practitioners to explore how the innovative use of these tools can strengthen health systems. Field experience with digital health interventions for TB is growing. The increased deployment of cutting-edge digital health concepts is destined to inject greater power, speed, flexibility and diversity into the same processes that have been helping public health practitioners, managers and clinicians to deliver better TB care to populations and patients for several decades. Improving the knowledge base on these experiences could increase opportunities for more of the successes and failures to be fed into a virtuous cycle of continuous quality improvement of digital interventions.

There is a need for better quality evidence for impact or efficiency from more rigorous studies that are directly relevant to TB programme implementation. Several digital health concepts still need to be tested under different conditions, including broader geographical spread, levels of decentralisation and models of care, and in a larger cross-section of patient subgroups. Certain digital activities are implemented on the basis of indirect evidence or experience imported from outside TB care, such as the monitoring of antiretroviral uptake [34-36] and smoking cessation programmes [37, 38]. Drawing parallels from outside the TB world can add value and is justified on the basis that the challenges of limited resources, such as the problems associated with stock management, supplies and logistics, cut across different disciplines. Inferences on behaviour change drawn from such analogies may, however, at times be obscured by imperfect comparison (such as the duration of treatment, safety profile of medicines used and stigma attached to TB). Conversely, there may be missed opportunities if the adoption and large-scale roll out of technological advances is put on hold until suitable studies have been devised and completed among TB patients. Given the imperative to link effectiveness with value for money, a sound "investment case" based on measured or modelled costs could build convincing arguments for specific interventions. This is particularly relevant for nascent technologies which have yet to attain the recognition needed to become integrated into mainstream activities or others that would need a significant outlay to take off.

One important question is: what type of evidence is required to support the operationalisation of digital health in TB programmes in future? And what kind of evidence would be recognised by implementers before a product is embedded in routine practice, including TB care and prevention [39]? Many trials are under way investigating different elements of mobile health [40]. Certain interventions lend themselves more easily to a prospective cohort study or randomised controlled trial (RCT) design than those for which impact is less straightforward to measure or is influenced by a number of external factors. These include interventions possessing parameters that can be fairly well standardised, for which the collection of quantitative data on both the intervention and the outcome is digitised and relatively discrete, which allow randomisation or where large numbers of study participants as well as comparison groups can be recruited. This may explain why initiatives involving mobile text messaging (Short Messaging Service (SMS)), medication monitors and VOT for adherence support have been studied more frequently under RCT conditions than others such as eLearning or laboratory information systems. Another closely related question relating to evidence is how much research will be needed before users are confident of the effectiveness or efficiency of an intervention? The ease with which data can nowadays be collected and stored during the operation of a digital tool paves the way for the prospect of continuous appraisal and validation, bringing processes such as routine surveillance based on electronic medical records within the reach of more users.

\section{Patient care}

Treatment of active TB requires daily administration of medicines for at least 6 months, and up to 2 years or more in the case of multidrug-resistant (MDR)-TB and extensively drug-resistant (XDR)-TB [41]. Erratic treatment adherence may lead to unfavourable outcomes with continued spread of infection, acquisition of drug resistance, disease chronicity, and death. Loss to follow-up could be alleviated if patients are better supported during their treatment $[42,43]$. Improved communication between patients and healthcare providers could thus increase patient engagement to adhere to treatment; ICT could facilitate bidirectional exchange. An added advantage is that the same medium of communication for patient-caregiver interaction could address other health risks that predispose to poor patient outcomes, such as smoking $[44,45]$. Action on social and behavioural risk factors is very much in line with the objects of pillar 2 (Bold policies and supporting systems) of the End TB Strategy [4]. The potential for digital health tools to deliver and monitor access to social support and, more specifically, social protection schemes like cash transfers, is largely untapped at the moment. The extensive global coverage of standardised TB programmes represents a unique opportunity to deliver other interventions at a time when patients may be particularly attuned to health messaging (e.g. smoking cessation to tobacco users). The long-term care of patients with MDR-TB and XDR-TB, some of whom are in need of palliative care, 
others of concomitant management of comorbidities such as HIV and diabetes, could benefit from existing and emerging digital health products.

As global connectivity expands, and hardware becomes more widely available and affordable, digital health products are destined to become increasingly present in the daily life of TB patients and practitioners. The potential for mobile phones to influence patient outcomes has been the subject of recent reviews [46, 47], one of which has looked specifically at evidence for the impact of SMS on TB adherence. Both reviews concluded that the evidence for the effectiveness of SMS-based interventions was not always clear: at times, no impact was registered, such as when SMS was used as a reminder. This lack of effect indicates that the design of future studies may need to test digital interventions within a wider range of behaviour-change techniques. High-quality evidence from RCTs is rare in this area and more has been published based on work from observational studies [48-52]. However, results from RCTs of mHealth and TB treatment adherence (including latent TB infection) conducted in very contrasting settings and using different applications, ranging from simple SMS to smartphone and online applications, are expected in the next few years [53-57]. Video interventions using phones have the potential to save resources when used to observe treatment and support patients [58-62]. Their feasibility is set to increase as Internet-enabled phones increasingly come to dominate the mobile phone markets, with low-resource countries expected to drive the incremental trend into the future [63]. Two ongoing RCTs are now investigating the effectiveness of VOT in TB patients using smartphones or other mobile digital devices [64, 65]; more are planned for the near future, including for the treatment of latent TB infection [66].

As various digital health products start to be developed in support of different components of TB programmes, it will be important to optimise their uptake at large scale. Even at the country level, it is becoming difficult, at times, to keep track of all the different initiatives, leading to underuse or wasteful parallel development of tools with a similar purpose. A one-stop Internet hub that links up to different services of relevance to TB care could serve to channel health professionals, patients and the wider public to an appropriate service (e.g. http://e-sanatate.md/). The end-product will not replace the triage or counselling roles of healthcare workers but will help them to locate resources better. This product may overlap with other tools being proposed in this report under the eLearning track (see the "eLearning" section later in this report, and TPPs 4.1 and 4.2); however, the primary intent of the Internet portal will be to inform about access rather than to promote learning.

The discussion on the digital health products for the "patient care" function thus focused on two items that were of particular interest at this juncture, namely: 1) VOT using mobile electronic devices to support TB patients on treatment; and 2) a common eHealth portal to inform TB patients and professionals about resources.

\section{Surveillance and monitoring}

Public health surveillance involves the continuous and systematic collection, analysis and interpretation of health-related data for planning, implementation and evaluation of public health practices [67]. It is one of the principal pillars of any functional public health system and an important tool for health action [68]. Effective surveillance will be needed to support the End TB strategy in the coming years [3], particularly through: measuring and monitoring the burden of disease and death, and determinants of TB, including risks such as tobacco use; measuring and monitoring the effectiveness of efforts to tackle the TB burden; reducing delays in TB care; monitoring drug safety; detecting and responding to TB outbreaks, including identifying "hot spots" and drug resistance, and interrupting the chain of transmission; planning for and managing resources such as TB medicines; guiding the planning, implementation, and evaluation of programmes and public policy to prevent TB; identifying gaps in knowledge and devising questions for research.

Implementing the core activities for a functional TB surveillance system often remains challenging in many countries due to a variety of factors, including: underdiagnosis or misdiagnosis of TB either through lack of access to health services or through poor diagnostic skills; inaccurate reporting and/or under-reporting of TB cases and inconsistent follow-up by frontline healthcare workers; inadequate use of the WHO standardised TB case definitions and reporting parameters [69]; TB notification may not be mandatory or, if it is, may not be enforced, with little motivation for the individual clinician (public or private) to notify; no coordination between different sources in the management of data useful for surveillance, including public and private sectors, insurance systems, laboratories, and hospital and outpatient facilities (these may have multiple information systems that live in silos and are not interoperable); weak culture of making use of programme data to inform decisions and often few efforts being made to have good quality data (e.g. by providing user feedback, updating the information and correcting mistakes); fragile health systems with limited resources, technology, human resources, knowledge, skills and time of frontline health workers due to various factors including competing duties, mismatching of an individual's skills with their job profile, inadequate pay, inefficient and error-prone paper-based processes, lack of feedback on the utilisation of the data, and lack of logistical and expert support. 
While general surveillance of TB often faces challenges in accuracy and completeness, the monitoring of TB drug safety tends to be even less developed globally. Many countries lack a functional drug-safety monitoring framework, as a result of weak health systems and the absence of a culture for routine monitoring of drug toxicity in TB programmes (in contrast for instance to TB drug resistance surveillance, which has been a mainstay for over 20 years [70]). This aspect of surveillance is now gaining importance within TB programmes as new drugs and novel regimens that incorporate repurposed medicines start to become available globally, particularly for MDR-TB and XDR-TB. These new interventions carry fresh hope for improved outcomes for patients. However, the safety profile of new medicines such as bedaquiline and delamanid, which were released on the market ahead of the completion of phase III trials, remains incomplete [71, 72]. The WHO policy on the use of these medicines recommends active monitoring for possible harm related to their use is in place. In 2015, WHO and main technical and financial partners defined the parameters for different levels of active drug-safety monitoring and management as they apply to the particular context of TB programmes [73, 74]. Development of basic but effective digital tools to collect and consolidate TB drug-safety data are thus in high demand at this point in time as countries prepare to expand their programmatic management of drug-resistant TB and avail of initiatives to facilitate access to new drugs (e.g. $[75,76])$.

For many of the problems related to the collection, management, safe storage and transmission of data, today's state-of-the-art in ICT can already offer transformative solutions [77-80]. However, information systems are tightly knitted to social, cultural, legal and working environments, and the introduction of new digital products may be perceived by people as a challenge and an intrusion into their work. The intended users are more likely to embrace change if they are convinced that it will bear tangible benefits. Thus, for instance, the flexibility for managers to access data securely from wherever they can get online could be an important selling point. As in any other areas of change management, introducing new digital products in surveillance and monitoring needs an enabling environment [81], which includes: support of senior management for change; sufficient resources for key functions such as training, software development, updates, testing and troubleshooting, and data storage; development of guidance and standard operating procedures; health policy changes (e.g. mandatory notification of infectious diseases to public health authorities); data policy, such as promotion of data standards and interoperability [82], the adoption of unique patient and provider identifiers to link data sets, and the adoption of standard data dictionaries; and a legal framework for data ownership and privacy to establish trust in information systems.

Streamlining the electronic health record and reducing tedious and time-consuming paperwork could support "eHealth readiness" [83]. The steady transition in the management of medical records and surveillance systems, from paper-based methods, through electronic systems installed on isolated computer terminals, to systems on local area networks and, now, Internet-accessible databases with storage of data on the cloud, is an evolution over a continuum that happened in the space of a few decades. Such processes are not easy to evaluate with efficacy trials. Nonetheless, basic principles that apply under comparable situations, such as how to protect patient confidentiality and ensure that data are valid, safely stored and not corrupted, need to be followed when implementing digital health interventions $[19,84]$. There are various measures that can be put in place to achieve this, ranging from automating error logs and crash reports (e.g. for electronic surveillance systems), building in user feedback modules (e.g. in eLearning packages), and holding regular audit reviews with system users to analyse critical episodes. Users intent upon introducing digital health interventions to facilitate their work would benefit from the description of best practices and lessons learnt narratives [85-87]. The effects described in such experiences could be modelled to illustrate their potential to save resources or to render a process more efficient. Implementation research to document gaps, bottlenecks, workarounds and good practices will be important for continued advancement [88-90].

TPPs for three products were proposed following the discussion in the consultation, namely: 1) an electronic dashboard of indicators and epidemiological trends relevant to TB; 2) digital notification of $\mathrm{TB}$ cases detected outside national TB programmes; and 3) digital tools to monitor the safety of TB drugs.

\section{Programme management}

Measuring the impact of ICT on programme management and building an evidence base around it pose similar challenges to those encountered in other areas of TB systems, given that the determinants of successful coordination and management are multifactorial. Indicators can nonetheless be identified to characterise the performance of certain elements of management. One such example is the influence of digital laboratory information systems (LISs) on the accuracy and turnaround time of test results [91, 92].

Diagnostic tests are an integral part of many public health interventions, guiding the detection of markers of disease and response to therapy. They have an important role in ensuring proper treatment, and avoiding unnecessary treatment and waste. In selecting the representative target product within the "programme management" function, the technical consultation focused on the performance of TB diagnostics as a domain of particular importance in modern TB care and which is now at a crucial 
juncture following the wide roll-out of self-contained systems that employ molecular methods functioning on digital platforms, such as GeneXpert (Cepheid, Sunnyvale, CA, USA) [93]. These units can work with a high accuracy even when operated by staff without formal laboratory training located in decentralised healthcare centres with basic facilities. However, inefficiencies in the management of data are being recognised as a bottleneck in the operation of these new diagnostics. In reaction, software that extracts and transmits data from GeneXpert machines has been developed and successfully implemented in recent years [94-97]. However, up to now, these software programmes have been narrowly focused on a single technology and work in isolation of other diagnostic equipment located at times within the same premises. They thus miss out on larger benefits to be gleaned from a more comprehensive system that manages information from various diagnostic processes and that can also handle rapid roll-out and decentralisation of the diagnostic capacity.

Reliable and timely information is of paramount importance for the proper functioning of several processes in the TB laboratory, ranging from the management of patient results data (i.e. emission to the requestor of the tests and their integration within electronic health records to facilitate clinical management), the quality assessment of testing, the monitoring of laboratory activity, and the generation of indicators for surveillance (by avoiding repeated enumeration of same samples from the same patient) [98]. Improving laboratory information also serves the "patient care" function, by reducing time for patients to receive results [99]. Projects aiming to implement LIS in low-resource settings have rarely advanced beyond the pilot or demonstration stages. One reason for this is that the chain of requirements necessary for its proper functioning at the scale of a country or a laboratory network often has weaknesses in one or more elements. The difficulty of sharing data between different diagnostic technologies has been one formidable hurdle, resulting from either insufficient knowledge or willingness by the manufacturers of equipment to render their machine software compliant with accepted standards that facilitate the interoperability of data without additional costs to the user (e.g. Health Level Seven (www.hl7.org) and LOINC (http://loinc.org)).

Figure 2 is a schematic representation of three critical stages in information management within a functional TB diagnostic facility. The first step represents the concept of "connected diagnostics", whereby data generated by different diagnostic equipment are routed through a single channel. This stage would be closely followed by the next two components, namely 1) the storage of data and 2) their transmission to the requesting clinician or to the electronic health record. The TPP described in this document relates only to the first step; once the concept has matured, it is planned to develop separate TPPs for the next two components in the logical sequence.

\section{eLearning}

eLearning is defined as "an approach to teaching and learning, representing all or part of the educational model applied, that is based on the use of electronic media and devices as tools for improving access to training, communication and interaction and that facilitates the adoption of new ways of understanding and developing learning" [100]. eLearning techniques range from support, to conventional learning (as a "blended" approach), to teaching that is delivered entirely online. Regardless of the technology applied, learning still remains its central element [101].

Innovations in eLearning, such as the application of game techniques to education (gamification), and technologies like augmented reality and three-dimensional learning environments, are challenging the time-honoured fundamentals of how new knowledge is acquired. For instance, some websites now promote

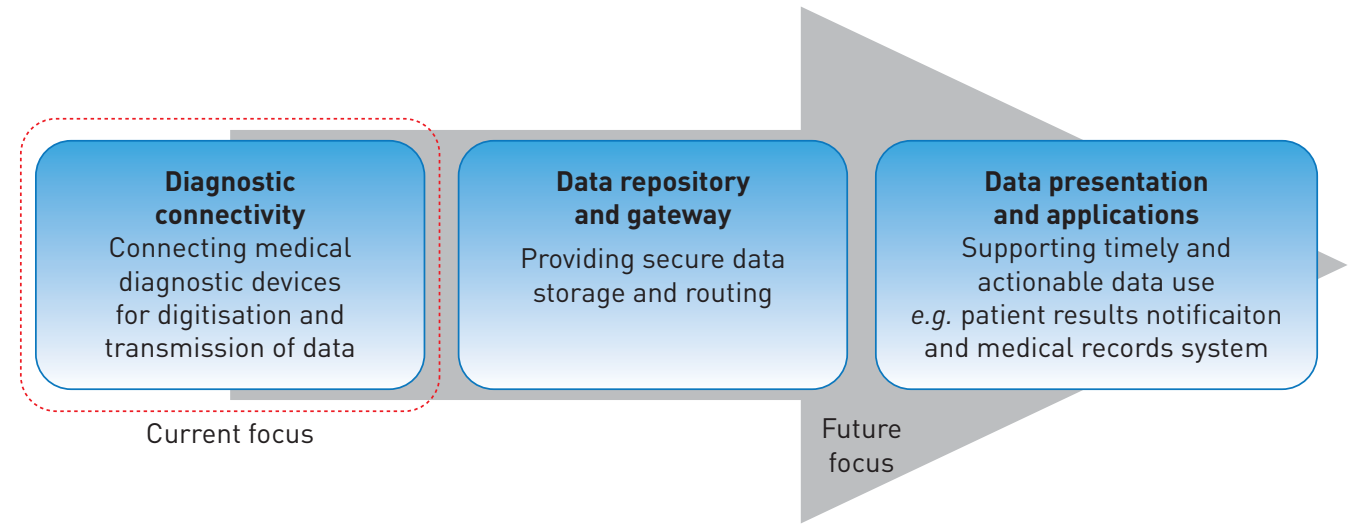

FIGURE 2 Schematic representation of the position of "diagnostic device connectivity" alongside other elements of a comprehensive laboratory information system for tuberculosis. 
the sharing of resources between frontline healthcare workers in peer-to-peer fashion (e.g. www.health-orb. org). Beyond eLearning as defined above, other resources, such as clinical decision support tools can assist health professionals to make a diagnosis or find the most suitable intervention in a particular patient interaction [102-104].

Both healthcare workers (formal or lay) and patients could benefit from new developments in learning techniques. In healthcare, the health needs of the population keep outpacing the health workforce availability and expertise, and eLearning presents many opportunities to close this gap. Reliable information about TB and other health risks could help patients and their relatives to cope better with the associated challenges. Clear and easy-to-understand messaging is expected to lead to a better informed decision when considering treatment options. Treatment of active TB involves the concomitant use of multiple medicines that often cause adverse effects that the patient should be aware of. Moreover, much of the evidence-based policy in TB care relies on low or very low quality data, which limits the strength of recommendations: in such a situation, aids would be of help for patients and professionals to make the most advantageous informed decision on care [105]. The combination of rapid access to a vast repertoire of online resources and the computational power of handheld devices now makes it possible to exploit more operational intelligence data when making a decision. This could ultimately improve a clinician's skills, just as eLearning delivers knowledge to a learner.

eLearning has the added advantage that it affords learners the luxury to work at their own pace and to follow their preferred educational pathways. When tutors are involved, these also stand to benefit from greater flexibility when compared to conventional training in organising their schedules and managing their time. eLearning is likely to reduce costs, improve the speed with which training and refresher courses are delivered, and permit access to a vast spread of resources, including novel curricula and experts. By virtue of their availability to a huge number of users across geographical space, eLearning products bear great promise as interventions that can be scaled up rapidly and efficiently.

Various sources for self-directed learning on TB management or smoking cessation are available online [106-114]. However, many such courses usually focus on one particular disease, and fail to capture a fuller spectrum of pulmonary conditions and other noncommunicable disease (NCD) risks that may be pertinent for the learner. The need for maintenance and updates of eLearning course material is often understated, and the quality and state of content of some sites may be poor. eLearning resources available today are still frequently text-heavy and not always customised for the virtual environment and for handheld devices in particular.

Published research comparing the outcomes of eLearning with more traditional methods of acquisition of knowledge in healthcare is still limited. However, there is a growing literature that supports the potential benefits for web-based training and use of multimedia techniques $[115,116]$, although there are only few reported studies that address synchronous eLearning programmes in medical education [117]. Online tobacco cessation courses have been reported by learners to improve ability and skills to counsel patients on tobacco cessation [118].

One of the risks of eLearning is the tendency for the depersonalisation of teaching and training. In some studies, dropout rates among eLearning students have been associated with feelings of isolation [119-124]. Greater interaction between eLearning participants may avert such situations [125].

Clinical decision support tools have been shown to influence the screening of patients at high risk of latent TB infection [126]. In another study, a clinical scoring system was found to be cost-effective for the diagnosis of smear-negative pulmonary TB [127]. Automating routines such as these could conceivably serve the practicing physician. Given the potential for such tools to improve the technical knowledge of the user, they have been included under the eLearning function.

Discussions during and after the WHO/ERS consultation identified three priority concepts for which TPPs could be usefully developed to support TB programmes. In the eLearning tools directed at both patients and professionals, antitobacco components feature prominently, given the impact that improved knowledge is expected to have on changing the behaviour of TB patients who smoke, alongside economic, environmental and organisational influences, and thus improving their treatment outcome. The TPPs were: 1) an online tool for patients and their relatives to learn about disease, treatment options, risk of transmission and associated health risks such as smoking (linked to TPP 1.2, which focuses on information on access rather than learning); 2) a comprehensive, web-based course on respiratory diseases, optimised for mobile devices and equipped with visual instruction aids aims to help building capacity and skills of health professionals in managing TB and reducing risks of negative outcomes (e.g. from smoking); and 3) a clinical decision-support tool to facilitate the daily work of practitioners and reduce the number of patients who receive suboptimal treatment. 


\section{Key steps in implementing digital health products for the End TB strategy}

As discussed, the introduction of novel digital health technologies into a setting needs to fit within the digital health landscape that exists or is planned for the health services [20]. There needs to be agreement on the nature of the problem to be addressed, its relative priority compared with other pressing needs and the expectations made of the solution being envisaged. These discussions would need to be held through an iterative process with all interested parties.

Several digital health products may contribute to different functions of the digital health framework for TB [13]. Thus, for instance, eLearning is instrumental to staff development and would help caregivers acquire new skills in digital concepts, LISs will contribute not only to "programme management" but also to "patient care" and to "surveillance and monitoring", while digital applications for drug-safety monitoring will be important for "patient care". Likewise, many of the digital health products identified will contribute variably to the different components of the End TB strategy (table 2 and figure 1) [4].

"Thinking digital" needs to become a recurring motif in discussions on how to align national TB strategic plans [128], TB guidelines, budgets, grant proposals and other documents to the concepts of the End TB Strategy. These processes should keep abreast of ICT advances and, mindful of the fast pace with which ICT evolves, ensure that solutions do not lose their edge between the time that they are conceived to when they get deployed. A sequence of key steps is proposed for decision-makers to follow when digital health is operationalised at the country level.

At the country level, influential deciders in the TB programme who have the vision, knowledge, authority and drive will champion the "digital health" cause and steward in the necessary developments. To act as true "agents of change", they need to be willing to address critical issues in the adaptation and uptake of digital health interventions [129]. Different concepts are unified into a single vision for the local context. A group of key stakeholders, representing TB, public health, ICT, mobile and Internet network providers, technical agencies, private caregivers, patients and donors, is required to advise in different areas. Multidisciplinary "consortia" of developers and designers, users, and donors could be assigned to specific tasks, and to develop particular concepts, and ensure their sustainability and, at times, commercial viability.

Pillar 2 components of the End TB Strategy (on "bold policies and supportive systems"), which lie beyond the span of control of TB programmes or even ministries of health, are a particular challenge. Nonetheless, digital health can provide opportunities to make significant inroads in this domain and can have a profound impact on many of the upstream determinants of TB. These include broader issues in lung health and in prevention of NCD, money transfers via mobiles to reward health-promoting behaviour and alleviate poverty, universal health care (e.g. unique digital identifiers, such as the e-AADHAAR project in India (https://uidai.gov.in)), and other contributors to health system strengthening.

Critical points are identified on the pathway to the successful implementation of the End TB Strategy at the national level. These can then be mapped to complementary digital health interventions that are suited to the problems. The interventions would need to be prioritised based on the dual considerations of 1) knowledge of their effectiveness and 2) programmatic circumstances, including feasibility, time to implementation, resource use, potential benefit, associated opportunities, support structure for particular technologies and "eHealth readiness", etc. The TPPs described in this article were identified through a similar process and could be a starting point for similar country-level discussions. The documentation (e.g. national strategic plan [128]) and any regulatory instruments (e.g. eHealth strategy [20]) that need to be created or updated should be targeted for specific focus.

Resources will be needed for implementation. The interventions can be mapped to various likely sources of funding to create sound "investment cases" for specific interventions. Such investments will be expected to generate dividends beyond TB and health; this needs to be emphasised in messaging and is of particular relevance in the SDG era [130]. Products that are either open source or operated under a model of socially responsible licensing would be preferred $[85,131,132]$. Building capacity and developing human resources necessary for the implementation of the End TB Strategy needs to factor in the additional requirements for the workforce of tomorrow to be conversant with ICT and its uses. Looking for in-country expertise can stimulate innovation and cultivate partnerships that are more likely to be sustainable than those depending heavily on external support.

A realistic timeline for implementation should be developed and new interventions validated in the local setting ahead of scale-up. The notion of feasibility at scale is an important consideration when prioritising products: interventions should not remain stuck in the pilot stage [133].

Operational research should be planned in advance to measure the uptake, utilisation (type and extent) and impact of the intervention on performance, including costs. It is a means to ensure adherence to good 
TABLE 2 Relative importance of digital health products targeted by the target product profiles to individual components of the End TB strategy

\begin{tabular}{|c|c|c|c|c|c|c|c|c|c|}
\hline \multirow{2}{*}{$\begin{array}{l}\text { End TB strategy pillars } \\
\text { and components }\end{array}$} & \multicolumn{2}{|c|}{ 1) Patient care } & \multicolumn{3}{|c|}{ 2) Surveillance and monitoring } & \multirow{2}{*}{$\begin{array}{l}\text { 3) Connected } \\
\text { diagnostics } \\
\text { for TB }\end{array}$} & \multicolumn{3}{|c|}{ 4) eLearning } \\
\hline & 1.1) VoT & $\begin{array}{l}\text { 1.2) Digital } \\
\text { health portal }\end{array}$ & $\begin{array}{l}\text { 2.1) Digital } \\
\text { notification }\end{array}$ & $\begin{array}{l}\text { 2.2) Electronic } \\
\text { dashboard }\end{array}$ & $\begin{array}{l}\text { 2.3) Drug safety } \\
\text { data capture }\end{array}$ & & $\begin{array}{l}\text { 4.1) Tools } \\
\text { for patients }\end{array}$ & $\begin{array}{l}\text { 4.2) Tools for } \\
\text { healthcare staff }\end{array}$ & $\begin{array}{l}\text { 4.3) Aids to } \\
\text { decision-making }\end{array}$ \\
\hline
\end{tabular}

1) Integrated, patient-centred

care and prevention

a) Early diagnosis of TB

including universal

drug-susceptibility

testing, and systematic

screening of contacts

and high-risk groups

b) Treatment of all people

with TB including

drug-resistant

tuberculosis, and patient

support

c) Collaborative TB/HIV

activities and

management of

comorbidities

d) Preventive treatment of persons at high risk and

vaccination against TB

2) Bold policies and

supportive systems

a) Political commitment

with adequate resources

for TB care and

prevention

b) Engagement of

communities, civil

society organisations,

and public and private

care providers

c) Universal health coverage

policy, and regulatory

frameworks for case

notification, vital

registration, quality and

rational use of

medicines, and infection

control

d) Social protection, poverty

alleviation and actions on

other determinants of TB 


\begin{tabular}{|c|c|c|c|c|c|c|c|c|c|}
\hline \multirow{2}{*}{$\begin{array}{l}\text { End TB strategy pillars } \\
\text { and components }\end{array}$} & \multicolumn{2}{|c|}{ 1) Patient care } & \multicolumn{3}{|c|}{ 2) Surveillance and monitoring } & \multirow{2}{*}{$\begin{array}{l}\text { 3) Connected } \\
\text { diagnostics } \\
\text { for TB }\end{array}$} & \multicolumn{3}{|c|}{ 4) eLearning } \\
\hline & 1.1) VOT & $\begin{array}{l}\text { 1.2) Digital } \\
\text { health portal }\end{array}$ & $\begin{array}{l}\text { 2.1) Digital } \\
\text { notification }\end{array}$ & $\begin{array}{l}\text { 2.2) Electronic } \\
\text { dashboard }\end{array}$ & $\begin{array}{l}\text { 2.3) Drug safety } \\
\text { data capture }\end{array}$ & & $\begin{array}{l}\text { 4.1) Tools } \\
\text { for patients }\end{array}$ & $\begin{array}{l}\text { 4.2) Tools for } \\
\text { healthcare staff }\end{array}$ & $\begin{array}{c}\text { 4.3) Aids to } \\
\text { decision-making }\end{array}$ \\
\hline \multicolumn{10}{|l|}{$\begin{array}{l}\text { 3) Intensified research and } \\
\text { innovation }\end{array}$} \\
\hline $\begin{array}{l}\text { a) Discovery, development } \\
\text { and rapid uptake of new } \\
\text { tools, interventions and } \\
\text { strategies }\end{array}$ & + & + & & & & ++ & ++ & ++ & ++ \\
\hline $\begin{array}{l}\text { b) Research to optimise } \\
\text { implementation and } \\
\text { impact, and promote } \\
\text { innovations }\end{array}$ & & & + & ++ & ++ & + & & & \\
\hline
\end{tabular}


practice, for instance, in data management and security during implementation [84]. Reporting of findings in a systematic manner would go some way to help strengthen the evidence base [90]. Lessons learnt would contribute to the third pillar of the End TB strategy ("intensified research and innovation"). Communication of findings would be of interest to both local and international workers.

\section{Conclusion and next steps}

Digital health interventions can strengthen health systems yet they remain underused [130]. In TB programmes, they need to be applied more consistently to improve patient care (e.g. support to adherence and efficient handling of medical records), surveillance and monitoring (e.g. improved notification, follow-up and drug-safety monitoring), programme management (e.g. laboratory management and drug procurement), and eLearning to enhance patient education and professional development [13]. In its diversity, ICT can contribute to all three pillars and 10 components of the End TB strategy [4]. This is particularly important in the first years of the post-2015 period, when TB programmes need to draw upon their creativity to optimise the effectiveness of currently available interventions to achieve the early targets slated for 2025 [2]. Digital health has far-reaching potential to help address more upstream determinants of $\mathrm{TB}$, such as the large-scale assignment of truly unique personal identifiers (e.g. e-AADHAAR), which not only enhances medical record keeping but also facilitates access of vulnerable populations to their social entitlements. Similarly, schemes to reward healthy behaviours can be mediated more readily when records and monetary transfers are automated. ICT will remain an important factor for the large-scale roll-out of new diagnostics and novel medicines; two examples of these applications in the last few years include the software successfully implemented for the transmission of result data from Xpert MTB/RIF and for active drug-safety monitoring for bedaquiline-implementing programmes. However, if not appropriately planned or implemented, digital health interventions could lead to failures, waste and disenchantment. Negative experiences may have long-standing repercussions and prejudice against broader efforts to automate work processes, depriving programmes of potential efficiencies and other benefits.

The application of digital health for TB presents the dual challenges of having to deal with rapidly evolving technologies that can offer new opportunities at every turn, and the need for the decision-makers and implementers to maintain a creative outlook when implementing a new strategy that demands a fundamental departure from previous approaches to TB control. However, in addition to following the rapidly advancing technology closely, the implementer is also in a position to evaluate the technology, and to help inform about when and how it is best applied. Increasing this body of evidence and the documented best practices on digital health will be an important resource for decision-makers, and needs to be enriched by more experience gathered systematically from the field of TB.

\section{Acknowledgements}

This article draws upon the deliberations of participants in four thematic working tracks at a technical consultation on the role of eHealth/mHealth in TB and tobacco control. This consultation was organised jointly by the Global TB Programme of the WHO and the ERS in Geneva, Switzerland on February 25-26, 2015 [11, 12]. This event led to the creation of "Digital health for the End TB Strategy: an agenda for action" [10], which was launched at the ERS International Congress in Amsterdam, the Netherlands, in September 2015.

The authors acknowledge, in particular, the following persons for their contributions to the consultation, the agenda for action and this article: Monica Dias and Kianoush Dheghani from the Global TB Programme of WHO (Geneva, Switzerland); and Virginia Arnold, Nathan Ford, Dongbo Fu, Garrett L. Mehl, Eyerusalem Negussie, Sameer Pujari and Diana Zandi from other WHO departments (Geneva, Switzerland). The full membership of the Global Task Force on Digital Health for TB is as follows: Giovanni Battista Migliori (ERS, Lausanne, Switzerland, and Fondazione S. Maugeri, Tradate, Italy); Ibrahim Abubakar (Public Health England, London, UK); Andrei Dadu (WHO/Europe, Copenhagen, Denmark); Claudia Denkinger (FIND, Geneva, Switzerland); Luis Gustavo do Valle Bastos (MSH, Medford, MA, USA); Tom Hiatt (WHO/Western Pacific Region, Manila, the Philippines); Richard Lester (University of British Columbia, Vancouver, BC, Canada); Janet Phillips (USAID, Washington, DC, USA); Subhi Quraishi (ZMQ Development, New Delhi, India); Kiran Kumar Rade (Revised National TB Control Programme, New Delhi, India); Valiantsin Rusovich (WHO Country Office, Minsk, Belarus); Daniel Stoller-Schai (Consultant on eLearning, Zurich, Switzerland); Alistair Story (Find and Treat, London, UK); Bruce V. Thomas (The Arcady Group, Richmond, VA, USA); Steve Uggowitzer (eSHIfT Partner Network, Entuura Ventures Ltd, Geneva, Switzerland); Dalene von Delft (TB Proof, Cape Town, South Africa); and Mohammed A. Yassin (Global Fund to Fight AIDS, Tuberculosis and Malaria, Geneva, Switzerland).

D. Falzon and H. Timimi were responsible for drafting the text of the article. D. Falzon organised the sections, figures, references and supplement, and submitted the manuscript for publication. The other authors provided substantive contributions to the text of the manuscript. All authors agree with the inferences made and conclusions drawn. D. Falzon, E. Jaramillo, V. Rusovich, H. Timimi, W. Van Gemert, K. Weyer, and M.C. Raviglione are WHO staff. They alone are responsible for the views expressed in this publication and they do not necessarily represent the decisions or policies of WHO. The designations used and the presentation of the material in this publication do not imply the expression of any opinion whatsoever on the part of WHO concerning the legal status of any country, territory, city or area, or of its authorities, nor concerning the delimitation of its frontiers or boundaries. M.A. Yassin is a staff member of the Global Fund to fight AIDS, Tuberculosis and Malaria (GFATM) and he alone is responsible for the views expressed in this publication and they do not necessarily represent the decisions or policies of GFATM. 


\section{References}

1 World Health Organization. Global tuberculosis report 2015 (WHO/HTM/TB/2015.22). http://apps.who.int/iris/ bitstream/10665/191102/1/9789241565059_eng.pdf Date last accessed: May 9, 2016.

2 World Health Organization. Resolution WHA67.1. Global strategy and targets for tuberculosis prevention, care and control after 2015. http://apps.who.int/gb/ebwha/pdf_files/WHA67/A67_R1-en.pdf Date last accessed: May 9, 2016. Uplekar M, Weil D, Lönnroth K, et al. WHO’s new End TB Strategy. Lancet 2015; 385: 1799-1801.

4 WHO Global TB Programme. Factsheet. The End TB Strategy. Global strategy and targets for tuberculosis prevention, care and control after 2015. www.who.int/tb/post2015_TBstrategy.pdf Date last accessed: May 9, 2016. United Nations Department of Economic and Social Affairs. Sustainable Development Goals. https:// sustainabledevelopment.un.org/sdgs Date last accessed: May 9, 2016.

6 United Nations General Assembly. Resolution A/RES/70/1. Tansforming our world: the 2030 Agenda for Sustainable Development. www.un.org/ga/search/view_doc.asp?symbol=A/RES/70/1\&Lang=E Date last accessed: May 9, 2016.

7 Denkinger CM, Grenier J, Stratis AK, et al. Mobile health to improve tuberculosis care and control: a call worth making. Int J Tuberc Lung Dis 2013; 17: 719-727.

8 Lönnroth K, Migliori GB, Abubakar I, et al. Towards tuberculosis elimination: an action framework for low-incidence countries. Eur Respir J 2015; 45: 928-952.

9 World Health Organization. Global Task Force on digital health for TB. www.who.int/tb/areas-of-work/ digital-health/global-task-force/en/ Date last accessed: November 20, 2015.

10 World Health Organization, European Respiratory Society. Digital health for the End TB Strategy: an agenda for action (WHO/HTM/TB/2015.21). www.who.int/tb/publications/digitalhealth-TB-agenda/en/ Date last accessed: May 9, 2016.

11 World Health Organization. The role of e/mHealth in tuberculosis and tobacco control : a WHO/ERS consultation. Meeting Report. (WHO/HTM/TB/2015.12). www.who.int/tb/features_archive/emHealthinTBandtobaccocontrol.pdf Date last accessed: May 9, 2016.

12 Falzon D, Raviglione M, Bel E, et al. The role of e/mHealth in tuberculosis and tobacco control : a WHO/ERS consultation. Eur Respir J 2015; 45: 307-311.

13 Dan North \& Associates. Introducing BDD. https://dannorth.net/introducing-bdd/ Date last accessed: May 3, 2016.

14 Guidance for Industry and Review Staff. Target Product Profile - A Strategic Development Process Tool. DRAFT GUIDANCE. www.fda.gov/downloads/drugs/guidancecomplianceregulatoryinformation/guidances/ucm080593.pdf Date last accessed: May 9, 2016.

15 Behavior-driven development. https://en.wikipedia.org/wiki/Behavior-driven_development Date last accessed: December 28, 2015.

16 Kik SV, Denkinger CM, Casenghi M, et al. Tuberculosis diagnostics: which target product profiles should be prioritised? Eur Respir J 2014; 44: 537-540.

17 World Health Organization. High-priority target product profiles for new tuberculosis diagnostics: report of a consensus meeting (WHO/HTM/TB/2014.18). http://apps.who.int/iris/bitstream/10665/135617/1/WHO_HTM_ TB 2014.18_eng.pdf Date last accessed: May 9, 2016.

18 Liu X, Lewis JJ, Zhang $\mathrm{H}$, et al. Effectiveness of electronic reminders to improve medication adherence in tuberculosis patients: a cluster-randomised trial. PLoS Med 2015; 12: e1001876.

19 Principles for Digital Development. http://digitalprinciples.org/ Date last accessed: November 14, 2015.

20 ITU. National eHealth Strategy Toolkit. www.itu.int/pub/D-STR-E_HEALTH.05-2012 Date last accessed July 16, 2012.

21 World Health Organization. Directory of eHealth policies. www.who.int/goe/policies/countries/en/ Date last accessed: May 9, 2016.

22 Diel R, Loddenkemper R, Zellweger J-P, et al. Old ideas to innovate tuberculosis control: preventive treatment to achieve elimination. Eur Respir J 2013; 42: 785-801.

23 D'Ambrosio L, Dara M, Tadolini M, et al. Tuberculosis elimination: theory and practice in Europe. Eur Respir J 2014; 43: 1410-1420.

24 Vrijens B, Urquhart J, White D. Electronically monitored dosing histories can be used to develop a medication-taking habit and manage patient adherence. Expert Rev Clin Pharmacol 2014; 7: 633-644.

25 Demonceau J, Ruppar T, Kristanto P, et al. Identification and assessment of adherence-enhancing interventions in studies assessing medication adherence through electronically compiled drug dosing histories: a systematic literature review and meta-analysis. Drugs 2013; 73: 545-562.

26 van den Boogaard J, Lyimo RA, Boeree MJ, et al. Electronic monitoring of treatment adherence and validation of alternative adherence measures in tuberculosis patients: a pilot study. Bull World Health Organ 2011; 89: 632-639. Maduskar P, Muyoyeta M, Ayles H, et al. Detection of tuberculosis using digital chest radiography: automated reading vs. interpretation by clinical officers. Int J Tuberc Lung Dis 2013; 17: 1613-1620.

28 QuanTB. SIAPS Program. http://siapsprogram.org/tools-and-guidance/quantb/ Date last accessed: November 20, 2015.

29 UNICEF. Acute Respiratory Infection Diagnostic Aid (ARIDA). www.innovateforchildren.org/sites/unicef.jjcdev2. com/files/ARIDA\%20-\%20Target\%20Product\%20Profile\%20-\%20Final_0.pdf Date last accessed: May 9, 2016.

30 Peer S, Fagan JJ. Hearing loss in the developing world: Evaluating the iPhone mobile device as a screening tool. South African Med J 2014; 105: 35.

31 Meredith SE, Robinson A, Erb P, et al. A mobile-phone-based breath carbon monoxide meter to detect cigarette smoking. Nicotine Tob Res 2014; 16: 766-773.

32 Breslauer DN, Maamari RN, Switz NA, et al. Mobile phone based clinical microscopy for global health applications. PLoS One 2009; 4: e6320.

33 International Telecommunications Union. ICT Facts and Figures. www.itu.int/en/ITU-D/Statistics/Documents/ facts/ICTFactsFigures2015.pdf Date last accessed: May 9, 2016.

34 Lester RT, Ritvo P, Mills EJ, et al. Effects of a mobile phone short message service on antiretroviral treatment adherence in Kenya (WelTel Kenya1): a randomised trial. Lancet 2010; 376: 1838-1845.

35 Haberer JE, Musiimenta A, Atukunda EC, et al. Short message service (SMS) reminders and real-time adherence monitoring improve antiretroviral therapy adherence in rural Uganda. AIDS 2016; 30: 1295-1300. 
Orrell C, Cohen K, Mauff $\mathrm{K}$, et al. A randomized controlled trial of real-time electronic adherence monitoring with text message dosing reminders in people starting first-line antiretroviral therapy. J AIDS 2015; 70: 495-502.

Civljak M, Stead LF, Hartmann-Boyce J, et al. Internet-based interventions for smoking cessation. Cochrane Database Syst Rev 2013; 7: CD007078.

Whittaker R, McRobbie H, Bullen C, et al. Mobile phone-based interventions for smoking cessation. Cochrane Database Syst Rev 2012; 11: CD006611.

Janssen R, Hettinga M, Prins H, et al. Developing evidence guidelines for eHealth Small and Medium-sized Enterprises. Towards feasible yet convincing evidence. www.windesheim.nl/ /media/files/windesheim/ research-publications/innovationroutesandevidenceguidelines.pdf Date last accessed: May 9, 2016.

Labrique A, Vasudevan L, Chang LW, et al. H_pe for mHealth: more ' $y$ ' or 'o' on the horizon? Int J Med Inform 2013; 82: 467-469.

World Health Organization. Companion handbook to the WHO guidelines for the programmatic management of drug-resistant tuberculosis (WHO/HTM/TB/2014.11). http://apps.who.int/iris/bitstream/10665/130918/1/978924 1548809_eng.pdf Date last accessed: May 9, 2016.

Munro SA, Lewin SA, Smith HJ, et al. Patient adherence to tuberculosis treatment: a systematic review of qualitative research. PLoS Med 2007; 4: e238.

Toczek A, Cox H, du Cros P, et al. Strategies for reducing treatment default in drug-resistant tuberculosis: systematic review and meta-analysis. Int J Tuberc Lung Dis 2013; 17: 299-307.

World Health Organization. A WHO/The UNION monograph on TB and tobacco control: joining efforts to control two related global epidemics (WHO/HTM/TB/2007.390). www.who.int/tobacco/resources/publications/ tb_tobac_monograph.pdf Date last accessed: May 9, 2016.

Lin H-H, Ezzati M, Murray M. Tobacco smoke, indoor air pollution and tuberculosis: a systematic review and meta-analysis. PLoS Med 2007; 4: e20.

Free C, Phillips G, Watson L, et al. The effectiveness of mobile-health technologies to improve health care service delivery processes: a systematic review and meta-analysis. PLoS Med 2013; 10: e1001363.

Nglazi MD, Bekker L-G, Wood R, et al. Mobile phone text messaging for promoting adherence to anti-tuberculosis treatment: a systematic review. BMC Infect Dis 2013; 13: 566.

Mohammed S, Siddiqi O, Ali O, et al. User engagement with and attitudes towards an interactive SMS reminder system for patients with tuberculosis. J Telemed Telecare 2012; 18: 404-408.

Albino S, Tabb KM, Requena D, et al. Perceptions and acceptability of short message services technology to improve treatment adherence amongst tuberculosis patients in Peru: a focus group study. PLoS One. 2014; 9: e95770x.

Lei X, Liu Q, Wang H, et al. Is the short messaging service feasible to improve adherence to tuberculosis care? A cross-sectional study. Trans R Soc Trop Med Hyg 2013; 107: 666-668.

Kunawararak P, Pongpanich S, Chantawong S, et al. Tuberculosis treatment with mobile-phone medication reminders in northern Thailand. Southeast Asian J Trop Med Public Health 2011; 42: 1444-1451.

Iribarren S, Chirico C, Echevarria M, et al. TextTB: A parallel design randomized control pilot study to evaluate acceptance and feasibility of a patient-driven mobile phone based intervention to support adherence to TB treatment. J Mob Technol Med 2012; 1: 23-24.

jiang S. Community trial of new methods in tuberculosis treatment management. www.isrctn.com/ ISRCTN46846388 Date last updated: September 16, 2016.

Mohammed S. Evaluating the Effectiveness of Interactive SMS Reminders on TB Drug Compliance and Treatment. https://clinicaltrials.gov/ct2/show/NCT01690754 Date last updated: March 18, 2016.

University of British Columbia. TB mHealth Study - Use of Cell Phones to Improve Compliance in Patients on LTBI Treatment. https://clinicaltrials.gov/show/NCT01549457 Date last updated: October 7, 2015.

Bediang G, Stoll B, Elia N, et al. SMS reminders to improve the tuberculosis cure rate in developing countries (TB-SMS Cameroon): a protocol of a randomised control study. Trials 2014; 15: 35.

Centers for Disease Control and Prevention. Study 33: Adherence to Latent Tuberculosis Infection Treatment 3HP SAT Versus 3HP DOT. https://clinicaltrials.gov/ct2/show/NCT01582711?term=tuberculosis+sms\&rank=1 Date last updated: July 30, 2015.

DeMaio J, Schwartz L, Cooley P, et al. The application of telemedicine technology to a directly observed therapy program for tuberculosis: a pilot project. Clin Infect Dis 2001; 33: 2082-2084.

Krueger K, Ruby D, Cooley P, et al. Videophone utilization as an alternative to directly observed therapy for tuberculosis. Int J Tuberc Lung Dis 2010; 14: 779-781.

UCSD Global Public Health. VCP DOT. http:/gph.ucsd.edu/research/active-projects/Pages/vcp-dot.aspx Date last accessed: May 9, 2016.

Garfein RS, Collins K, Muñoz F, et al. Feasibility of tuberculosis treatment monitoring by video directly observed therapy: a binational pilot study. Int J Tuberc Lung Dis 2015; 19: 1057-1064.

Story A, Garfein RS, Hayward A, et al. Monitoring Therapy Adherence of Tuberculosis Patients by using Video-Enabled Electronic Devices. Emerg Infect Dis 2016; 22: 538.

GSMA. The Mobile Economy 2015. London, GSMA, 2015. https://clinicaltrials.gov/ct2/show/NCT02331732 Date last updated: September 23, 2015.

Hayward A. TB Reach 5: to compare the efficacy of video observed treatment (VOT) versus directly observed treatment (DOT) in supporting adherence in patients with active tuberculosis. www.isrctn.com/ISRCTN26184967 Date last updated: April 22, 2015.

NIH RePORTER. Project Information - NIH Research Portfolio Online Reporting Tools Expenditures and Results. https://projectreporter.nih.gov/project_info_description.cfm?aid=8848622\&icde=27233251\&ddparam $=$ \& ddvalue $=\& d d s u b=\& c r=1 \& c s b=$ default $\& c s=$ ASC Date last accessed: May 9, 2016.

World Health Organization. Public health surveillance. www.who.int/topics/public_health_surveillance/en/ Date last accessed: November 21, 2015.

Wetterhall SF, Pappaioanou M, Thacker SB, et al. The role of public health surveillance: information for effective action in public health. MMWR Morb Mortal Wkly Rep 1992; 41: Suppl., 207-218. 
World Health Organization. Definitions and reporting framework for tuberculosis - 2013 revision (WHO/HTM/ TB/2013.2). www.who.int/iris/bitstream/10665/79199/1/9789241505345_eng.pdf Date last accessed: May 9, 2016. World Health Organization. Global tuberculosis report 2014 (WHO/HTM/TB/2014.08). www.who.int/tb/ publications/global_report/gtbr14_main_text.pdf Date last accessed: May 9, 2016.

World Health Organization. The use of bedaquiline in the treatment of multidrug-resistant tuberculosis. Interim policy guidance (WHO/HTM/TB/2013.6). http://apps.who.int/iris/bitstream/10665/84879/1/9789241505482_eng.pdf Date last accessed: May 9, 2016.

World Health Organization. The use of delamanid in the treatment of multidrug-resistant tuberculosis. Interim policy guidance (WHO/HTM/TB/2014.23). http://apps.who.int/iris/bitstream/10665/137334/1/WHO_HTM_TB_ 2014.23_eng.pdf Date last accessed: May 9, 2016.

World Health Organization. Inter-regional workshop on pharmacovigilance for new drugs and novel regimens for the treatment of drug-resistant tuberculosis. Meeting Report. 12-14 November 2014. Hanoi, Viet Nam (WHO/ HTM/TB/2015.07). www.who.int/entity/tb/challenges/meeting_report_pv_workshop_hanoi_2014.pdf Date last accessed: May 9, 2016.

World Health Organization. Active tuberculosis drug-safety monitoring and management (aDSM). Framework for implementation (WHO/HTM/TB/2015.28). http://apps.who.int/iris/bitstream/10665/204465/1/WHO_HTM_ TB_2015.28_eng.pdf Date last accessed: May 9, 2016.

USAID. USAID's Bedaquiline Donation Program in Partnership with Johnson and Johnson. www.usaid.gov/ what-we-do/global-health/tuberculosis/technical-areas/bedaquiline-donation-program Date last accessed: November 27, 2015.

PViMS. Brochure1. http://apps.who.int/medicinedocs /documents/s22248en/s22248en.pdf

Labrique AB, Vasudevan L, Kochi E, et al. mHealth innovations as health system strengthening tools: 12 common applications and a visual framework. Glob Health Sci Pract 2013; 1: 160-171.

Calderwood MS, Platt R, Hou X, et al. Real-time surveillance for tuberculosis using electronic health record data from an ambulatory practice in eastern Massachusetts. Public Health Rep 2010; 125: 843-850.

Lazarus R, Klompas M, Campion FX, et al. Electronic support for public health: validated case finding and reporting for notifiable diseases using electronic medical data. J Am Med Inform Assoc 2009; 16: 18-24.

World Health Organization. Health in 2015: from MDGs, Millennium Development Goals to SDGs, Sustainable Development Goals. http://apps.who.int/iris/bitstream/10665/200009/1/9789241565110_eng.pdf?ua=1 Date last accessed: May 9, 2016.

Statnikova K. Information technology implementation: what works and what does not (MSc Management of Technology). http://etd.library.vanderbilt.edu/available/etd-04012005-210048/unrestricted/statnikova.pdf Date last accessed: May 9, 2016.

World Health Organization. Resolution WHA66.24. eHealth standardization and interoperability. www.who.int/ ehealth/events/wha66_r24-en.pdf Date last accessed: May 9, 2016.

Li J, Land LPW, Chattopadhyay S, et al. E-Health readiness framework from Electronic Health records perspective. http://citeseerx.ist.psu.edu/viewdoc/download?doi=10.1.1.528.5038\&rep=rep1\&type=pdf Date last accessed: May 9, 2016.

Timimi H, Falzon D, Glaziou P, et al. WHO guidance on electronic systems to manage data for tuberculosis care and control. J Am Med Inform Assoc 2012; 19: 939-941.

World Health Organization. Electronic recording and reporting for tuberculosis care and control (WHO/HTM/ TB/2011.22). http://whqlibdoc.who.int/publications/2012/9789241564465_eng.pdf Date last accessed: May 9, 2016.

Braa J, Heywood A, Sahay S. Improving quality and use of data through data-use workshops: Zanzibar, United Republic of Tanzania. Bull World Health Organ 2012; 90: 379-384.

Huang F, Cheng S, Du X, et al. Electronic recording and reporting system for tuberculosis in China: experience and opportunities. J Am Med Inform Assoc 2014; 21: 938-941.

Cobelens F, van Kampen S, Ochodo E, et al. Research on implementation of interventions in tuberculosis control in low- and middle-income countries: a systematic review. PLoS Med 2012; 9: e1001358.

Squire SB, Ramsay ARC, van den Hof S, et al. Making innovations accessible to the poor through implementation research. Int J Tuberc Lung Dis 2011; 15: 862-870.

Hales S, Lesher-Trevino A, Ford N, et al. Reporting guidelines for implementation and operational research. Bull World Health Organ 2016; 94: 58-64.

Blaya JA, Shin SS, Yagui MJA, et al. Assessing effects of the e-Chasqui laboratory information system on accuracy and timeliness of bacteriology results in the Peruvian tuberculosis program. AMIA Annu Symp Proc 2007; 873.

Seidenberg P, Nicholson S, Schaefer M, et al. Early infant diagnosis of HIV infection in Zambia through mobile phone texting of blood test results. Bull World Health Organ 2012; 90: 348-356.

Weyer K, Mirzayev F, Migliori GB, et al. Rapid molecular TB diagnosis: evidence, policy making and global implementation of Xpert MTB/RIF. Eur Respir J 2013; 42: 252-257.

Cepheid. RemoteXpert Platform. http://manas.com.ar/projects/cepheid-xpert-platform/ Date last accessed: May 9, 2016.

GxAlert. Connecting rapid diagnosis with better health outcomes. www.gxalert.com/ Date last accessed: May 3, 2015. XpertSMS. Automated Reporting of GeneXpert Results. www.ihsinformatics.com/xpert-sms Date last accessed: May 3, 2015.

Savics. GenXchange. www.savics.org/genxchange/ Date last accessed: February 1, 2016.

World Health Organization. Implementing tuberculosis diagnostics: a policy framework (WHO/HTM/TB/2015.11). http://apps.who.int/iris/bitstream/10665/162712/1/9789241508612_eng.pdf Date last accessed: May 9, 2016.

Swendeman D, Rotheram-Borus MJ. Innovation in sexually transmitted disease and HIV prevention: Internet and mobile phone delivery vehicles for global diffusion. Curr Opin Psychiatry 2010; 23: 139-144.

Sangrà A, Vlachopoulos D, Cabrera N. Building an inclusive definition of e-learning: an approach to the conceptual framework. Int Rev Res Open Distributed Learning 2012; 13: 145-159.

JISC. e-Learning programme. www.webarchive.org.uk/wayback/archive/20140614020907/http://www.jisc.ac.uk/ whatwedo/programmes/elearning.aspx Date last accessed: May 1, 2015. 
The Online TST/IGRA Interpreter. www.tstin3d.com/en/calc.html Date last accessed: November 27, 2015. Open Clinical. Decision Support Systems. www.openclinical.org/dss.html Date last accessed: May 1, 2015. Berner ES, ed. Clinical Decision Support Systems. New York, Springer New York, 2007.

Guyatt GH, Oxman AD, Kunz R, et al. Going from evidence to recommendations. BMJ 2008; 336: $1049-1051$. International Council of Nurses. Care, prevention and management of tuberculosis - home. www.cetl.org.uk/ learning/tb/index.html Date last accessed: May 1, 2015.

Global Health eLearning Center. Tuberculosis Basics (Update). www.globalhealthlearning.org/course/tuberculosisbasics-update Date last accessed: May 1, 2015.

NCSCT. Online training. http://elearning.ncsct.co.uk/free Date last accessed: May 1, 2015.

UCSF. Rx for change. http://rxforchange.ucsf.edu/ Date last accessed: May 1, 2015.

Global Tobacco Control. Learning from the Experts: A Course for Healthcare Professionals. http://hp. globaltobaccocontrol.org/online_training Date last accessed: May 1, 2015.

ATTUD. Accredited Programs. http://ctttp.org/ Date last accessed: May 1, 2015.

LearnOnline. http://learnonline.health.nz/index.php Date last accessed: May 1, 2015.

Quit Victoria. Learning Hub. www.quit.org.au/learning-hub/ Date last accessed: May 1, 2015.

World Health Organization, The Union. Childhood TB: Training Toolkit. www.who.int/tb/challenges/ childtbtraining_manual/en/ Date last accessed: May 9, 2016.

1998; 134: 725-728.

Bell DS, Fonarow GC, Hays RD, et al. Self-study from web-based and printed guideline materials. a randomized, controlled trial among resident physicians. Ann Intern Med 2000; 132: 938-946.

Lau F, Bates J. A review of e-learning practices for undergraduate medical education. J Med Syst 2004; 28 : 71-87.

Schmelz AN, Nixon B, McDaniel A, et al. Evaluation of an Online Tobacco Cessation Course for Health Professions Students. Am J Pharm Educ 2010; 74: 36.

Besser H, Donahue S. Introduction and overview. J Am Soc Inform Sci 1996; 47: 801-804.

Cookson PS. Learners: Research on learners and learning in distance education: a review. Am J Distance Educ 1989; 3: 22-34.

Galusha JM. Barriers to Learning in Distance Education. http://eric.ed.gov/?id=ED416377 Date last accessed: May 9, 2016.

Hara N, Kling R. Students' frustrations with a Web-based distance education course. First Monday 1999; 4: DOI $10.5210 /$ fm.v4i12.710

Lockett K. The loneliness of the long distance learners? Using online student support to decrease the isolation factor and increase motivation. In Orlando, Florida, US, Association for Advancement of Computing in Education, 1998.http://files.eric.ed.gov/fulltext/ED427680.pdf Date last accessed: May 1, 2015.

Al-Shorbaji N, Atun R, Car J, et al. eLearning for undergraduate health professional education: a systematic review informing a radical transformation of health workforce development. www.who.int/hrh/documents/ 14126-eLearningReport.pdf Date last accessed: May 9, 2016.

Lee O, Im Y. Students' perception on e-learning in tertiary level education. www.iet-c.net/publication folder/ietc/ ietc2001.pdf

Steele AW, Eisert S, Davidson A, et al. Using computerized clinical decision support for latent tuberculosis infection screening. Am J Prev Med 2005; 28: 281-284.

Soto A, Solari L, Agapito J, et al. Development of a clinical scoring system for the diagnosis of smear-negative pulmonary tuberculosis. Braz J Infect Dis 2008; 12: 128-132.

World Health Organization. Toolkit to develop a National Strategic Plan for TB prevention, care and control. Methodology on how to develop a national strategic plan (WHO/HTM/TB/2015.08) www.who.int/tb/ publications/NSP_toolkit/en/ Date last accessed: May 9, 2016.

Li J, Talaei-Khoei A, Seale H, et al. Health Care Provider Adoption of eHealth: Systematic Literature Review. Interact J Med Res 2013; 2: e7.

The World Bank. World Development Report 2016: Digital Dividends. www.worldbank.org/en/publication/ wdr2016 Date last accessed: February 1, 2016.

Wasan KM, Thornton SJ, Bell I, et al. The global access initiative at the University of British Columbia (UBC): availability of UBC discoveries and technologies to the developing world. J Pharm Sci 2009; 98: 791-794.

Guebert JM, Bubela T. Implemen
Sci Transl Med 2014; 6: $260 \mathrm{~cm} 11$. ExpandNet-WHO\%20Nine\%20Step\%20Guide\%20published.pdf Date last accessed: May 9, 2016. 